\title{
Depression in Mild Cognitive Impairment is associated with Progression to Alzheimer's Disease: A Longitudinal Study
}

\author{
Stefan Van der Mussele ${ }^{\mathrm{a}, \mathrm{b}}$, Erik Fransen $^{\mathrm{c}}$, Hanne Struyfs $^{\mathrm{a}}$, Jill Luyckx ${ }^{\mathrm{a}}$, Peter Mariën ${ }^{\mathrm{d}, \mathrm{e}}$, Jos Saerens $^{\mathrm{d}}$, \\ Nore Somers $^{\mathrm{d}}$, Johan Goeman ${ }^{\mathrm{d}}$, Peter P. De Deyn ${ }^{\mathrm{a}, \mathrm{d}, \mathrm{f}, \mathrm{g}}$ and Sebastiaan Engelborghs ${ }^{\mathrm{a}, \mathrm{d}, *}$ \\ ${ }^{a}$ Reference Center for Biological Markers of Dementia (BIODEM), Laboratory of Neurochemistry and Behavior, \\ Institute Born-Bunge, University of Antwerp, Antwerp, Belgium \\ ${ }^{\mathrm{b}}$ Department of Nursing and Midwifery Sciences, Faculty of Medicine and Health Sciences, University of Antwerp, \\ Antwerp, Belgium \\ ${ }^{\mathrm{c}}$ StatUa Center for Statistics, University of Antwerp, Antwerp, Belgium \\ ${ }^{\mathrm{d}}$ Department of Neurology and Memory Clinic, Hospital Network Antwerp (ZNA), Middelheim and Hoge Beuken, \\ Antwerp, Belgium \\ ${ }^{\mathrm{e}}$ Department of Clinical and Experimental Neurolinguistics (CLIN), Vrije Universiteit Brussel, Brussels, Belgium \\ ${ }^{\mathrm{f}}$ Department of Rehabilitation Sciences and Physiotherapy, Faculty of Medicine and Health Sciences, University \\ of Antwerp, Antwerp, Belgium \\ ${ }^{\mathrm{g}}$ Department of Neurology and Alzheimer Research Center, University Medical Center Groningen, \\ University of Groningen, The Netherlands
}

Accepted 8 May 2014

\begin{abstract}
.
Background: Behavioral and psychological signs and symptoms of dementia (BPSD) belong to the core symptoms of dementia and are also common in mild cognitive impairment (MCI).

Objective: This study would like to contribute to the understanding of the prognostic role of BPSD in MCI for the progression to dementia due to Alzheimer's disease (AD).

Methods: Data were generated through an ongoing prospective longitudinal study on BPSD. Assessment was performed by means of the Middelheim Frontality Score, Behave-AD, Cohen-Mansfield Agitation Inventory, Cornell Scale for Depression in Dementia (CSDD), and Geriatric Depression Scale 30-questions (GDS-30). Cox proportional hazard models were used to test the hypothesis that certain BPSD in MCI are predictors of developing AD.

Results: The study population consisted of $183 \mathrm{MCI}$ patients at baseline. At follow-up, 74 patients were stable and 109 patients progressed to AD. The presence of significant depressive symptoms in MCI as measured by the CSDD (HR: 2.06; 95\% CI: $1.23-3.44 ; p=0.011$ ) and the GDS-30 (HR: $1.77 ; 95 \%$ CI: $1.10-2.85 ; p=0.025$ ) were associated with progression to AD. The severity of depressive symptoms as measured by the GDS-30 was a predictor for progression too (HR: 1.06; 95\% CI: 1.01-1.11; $p=0.020$ ). Furthermore, the severity of agitated behavior, especially verbal agitation and the presence of purposeless activity, was also associated with progression, whereas diurnal rhythm disturbances were associated with no progression to AD.

Conclusion: Depressive symptoms in MCI appear to be predictors for progression to AD.
\end{abstract}

Keywords: Alzheimer's disease, association, BPSD, Cox proportional hazard, dementia, depression, depressive symptoms, mild cognitive impairment, predictor, prognostic value

\footnotetext{
${ }^{*}$ Correspondence to: Dr. Sebastiaan Engelborghs, MD, PhD, University of Antwerp/Institute Born-Bunge; Reference Center for Biological Markers of Dementia (BIODEM), Universiteitsplein 1, BE-2610 Antwerp, Belgium. Tel.: +32 326525 96; Fax: +32 3265 26 18; E-mail: Sebastiaan.Engelborghs@uantwerpen.be.
} 


\section{INTRODUCTION}

Mild cognitive impairment (MCI) is a clinical concept that identifies subjects who are in an intermediate cognitive state between normal aging and dementia. MCI is a syndrome characterized by an impairment of memory or other cognitive decline, which does not affect a person's basic activities of daily living, whereas the complex instrumental functions may be minimally impaired. MCI can be divided into two subtypes: an amnestic subtype with memory deficits and a nonamnestic subtype with a cognitive decline other than memory. The subtypes can be further specified, based on cognitive impairment in a 'single domain' or in 'multiple domains' $[1,2]$.

The clinical presentation, etiology, and outcome of MCI are heterogeneous. The etiology can be neurodegenerative, vascular, metabolic, traumatic, psychiatric, or other $[1,2]$. Furthermore, patients with amnestic MCI are likely to progress to dementia due to Alzheimer's disease (AD) [3], whereas the outcome of non-amnestic MCI appears to be more heterogeneous, including vascular dementia, frontotemporal dementia, and dementia with Lewy bodies [1]. However, not all MCI patients progress to dementia and some recover to normal cognition [2]. This can at least partially be explained by the fact that elderly with depression and cognitive symptoms were diagnosed as MCI in some studies [4]. It is assumed that less than half of the MCI patients develop a type of dementia and the annual rate of MCI progression to dementia is approximately 5-10\% [5]. However, the progression rate is influenced by the MCI definition used, the MCI subtype and the research setting [5].

Behavioral and psychological signs and symptoms of dementia (BPSD) belong to the core symptoms of dementia [6], but BPSD are also common in MCI with reported prevalence ranging from $35 \%$ to $85 \%$ [7-10]. Moreover, certain BPSD are also more prevalent and severe in MCI than in cognitively healthy older adults, but less prevalent and severe in MCI than in AD [7]. Given the high prevalence of BPSD in MCI and AD and given the intermediate BPSD state of MCI between healthy older adults and AD [7], it is possible that some of these symptoms are predictors of progression from MCI to AD.

Therefore, large prospective longitudinal studies are needed for improved understanding of the prognostic value of neuropsychiatric features in MCI for the progression to dementia $[9,10]$. With this study, we would like to contribute to the understanding of the epidemiology of MCI, the diagnostic value of BPSD in MCI and the evaluation of the prognostic role of BPSD in MCI for the progression to AD. We hypothesize that $\mathrm{BPSD}$ in MCI are predictors for the progression to AD.

\section{MATERIALS AND METHODS}

\section{Study population and diagnostic criteria}

This monocenter study included patients at the moment of their diagnostic work-up in a tertiary care level memory clinic. The diagnostic work-up consisted of a general physical and neurological examination, routine blood examination, structural neuroimaging consisting of brain magnetic resonance imaging or, if not feasible, brain computerized tomography, standard electroencephalogram, the Mini-Mental State Examination (MMSE) [11], and an extensive time-linked ( \pm 3 months) neuropsychological examination with adjustment for gender, age, and education, comprising among others the Wechsler Memory Scale III [12], Repeatable Battery for the Assessment of Neuropsychological Status [13], and/or Hierarchic Dementia Scale [14].

To diagnose MCI at baseline, Petersen's diagnostic criteria [1] were applied, i.e., (1) cognitive complaint, preferably corroborated by an informant; (2) objective cognitive impairment, quantified as a performance of more than 1.5 SD below the appropriate mean on the neuropsychological subtests; (3) largely normal general cognitive functioning; (4) essentially intact activities of daily living (basic and instrumental activities of daily living were determined by a clinical interview with the patient and an informant); and (5) not demented. As all cognitive domains of subjects were tested in an extensive time-linked $( \pm 3$ months) neuropsychological examination, all MCI patients were categorized as: an 'amnestic' subtype with memory deficits or a 'non-amnestic' subtype with cognitive decline other than memory; and cognitive impairment could be present in a 'single domain' or in 'multiple domains'. Patients with neurological, psychiatric, or somatic disorders that were a sufficient cause for the cognitive complaints, such as alcohol abuse or severe depression, were excluded. Severe depression at baseline was defined as a Cornell Scale for Depression in Dementia (CSDD) total score of $\geq 22$ or a Geriatric Depression Scale 30 questions (GDS-30) total score of $\geq 21$. Study participants were 55 years of age minimum and had a clinical follow-up of at least one year or until dementia diagnosis.

In total our database contained data on 589 patients recruited for cognitive impairment (not demented) 
BPSD research purposes since 2003. After strict application of the MCI Petersen criteria, 303 patients were eligible. From this cohort, 235 MCI patients met the study criteria. Only 5 subjects dropped out due to the criterion 'severe depression at baseline'. Two of them remained non-amnestic single domain MCI over time, one subject normalized, one progressed to frontotemporal lobar degeneration and only one patient progressed to $\mathrm{AD}$. To diagnose probable $\mathrm{AD}$ at followup, the NINCDS/ADRDA criteria [15] were used, though all patients also fulfilled the DSM-IV-TR criteria [16]. Clinical and neuropsychological follow-up of included patients and autopsy in deceased patients during follow-up who consented [17], further contributed to the diagnostic accuracy of the subjects in this study.

Staging of cognitive deterioration was assessed by means of the Global Deterioration Scale [18]. Age at disease onset was estimated by the clinician following an interview with the patient's main caregiver. In case a non-professional caregiver was not available, the patient's main professional caregiver was contacted and interviewed.

The local ethics committee approved this study. All patients and/or patients' caregivers gave written informed consent. All patients were of Caucasian origin.

\section{BPSD assessment}

All subjects underwent in-depth BPSD assessment at inclusion (baseline) consisting of an interview of both patient and caregiver, covering a period of two weeks prior to inclusion. The battery of BPSD assessment scales comprised: Middelheim Frontality Score (MFS), Behavioral Pathology in Alzheimer's Disease Rating Scale (Behave-AD), Cohen-Mansfield Agitation Inventory (CMAI), CSDD, and GDS-30.

The MFS is a validated assessment scale that measures frontal lobe features and reliably discriminates FTD from AD patients with a sensitivity and specificity of almost $90 \%$ and with good inter- and intra-rater reliability $[19,20]$. According to the Instructions for Administration and Scoring, the MFS was rated by the clinician or researcher and was obtained by summating scores in a standardized fashion on ten items. Each item was scored either zero (absent) or one (present) yielding a total maximal score of 10 . The items scored are: (1) initially comparatively spared memory and spatial abilities; (2) Loss of insight and judgment; (3) disinhibition; (4) dietary hyperactivity; (5) changes in sexual behavior; (6) stereotyped behavior; (7) impaired control of emotions, euphoria or emotional bluntness; (8) aspontaneity; (9) speech disturbances such as stereotyped phrases, logorrhoea, mutism, echolalia; and (10) restlessness. The presence of frontal lobe symptoms in our study subjects was determined to be significant by a discriminatory cut-off of a total MFS score of $\geq 5$ [20].

The Behave-AD is a 25 -item scale that measures BPSD in seven clusters (Table 2), scored on a fourpoint scale of increasing severity [21]. Besides a total score, a global score on a four-point scale of increasing severity is provided, reflecting how troubling to the caregiver or dangerous to the patient the BPSD are, from not troubling or not dangerous (score 0 ) to severely troubling or dangerous (score 3 ). We dichotomized the severity scores to calculate prevalence percentages for Behave-AD clusters, total score and global score. Within the anxieties/phobias cluster, four types of anxiety symptoms are assessed which include; anxiety regarding upcoming events ('Godot syndrome'), fear of being left alone, other anxieties and other phobias which are each rated according to severity as outlined above. The activity disturbances cluster includes three items; wandering away from home, purposeless activity and inappropriate activity. We found it important to dissect these two Behave-AD clusters, as we believed that their individual items could be of prognostic value. It is farfetched to analyze the delusion or hallucination items, one cluster is a one-item cluster and other clusters are, besides in the Behave$\mathrm{AD}$, thoroughly discussed in the other more specific assessment scales.

The CMAI assesses 29 agitated behaviors on a seven-point scale of increasing frequency $(1=$ never to $7=$ several times an hour) [22]. CMAI cluster scores include aggressive behavior (10 items), physically nonaggressive behavior (11 items) and verbally agitated behavior (8 items); a total score is provided as well. Agitation was considered to be clinically relevant when one or more items occurred at least once a week (any individual item score $\geq 3$ ). Aggressive, physically non-aggressive and verbally agitated behavior was considered to be clinically relevant when one or more items within the respective cluster occurred at least once a week [23-29].

Depressive symptoms were assessed by means of the CSDD and the GDS-30. The CSDD is a 19item depression scale [30]. Item scores range from 0 (absent) to 2 (severe), with a maximum total score of 38 points. The items are clustered in five groups: (A) mood-related signs: anxiety, sadness and lack of reactivity to pleasant events; (B) behavioral disturbances: agitation, retardation, multiple physical 
Table 1

Baseline population characteristics

\begin{tabular}{|c|c|c|c|c|}
\hline & Total $n=183$ & Stable MCI $n=74$ & Progression AD $n=109$ & Statistics \\
\hline Male / Female & $77 / 106$ & $35 / 39$ & $42 / 67$ & $p=0.239$ \\
\hline Age at inclusion (y) & $74.9 \pm 7.5(55-91)$ & $72.0 \pm 8.0(55-88)$ & $76.9 \pm 6.5(58-91)$ & $p<0.001$ \\
\hline Age at onset (y) & $72.1 \pm 7.8(53-90)$ & $69.1 \pm 8.3(53-85)$ & $74.1 \pm 6.8(56-90)$ & $p<0.001$ \\
\hline Disease duration (y) & $2.7 \pm 1.8(0-14)$ & $2.7 \pm 1.9(0-10)$ & $2.7 \pm 1.8(0-14)$ & $p=0.776$ \\
\hline Education $(\mathrm{y} ; n=147)$ & $10.9 \pm 2.6(6-17)$ & $10.6 \pm 2.6(6-16 ; n=68)$ & $11.2 \pm 2.6(6-17 ; n=79)$ & $p=0.173$ \\
\hline MMSE score $(0-30)$ & $26.0 \pm 2.8(18-30)$ & $27.0 \pm 2.5(20-30)$ & $25.3 \pm 2.7(18-30)$ & $p<0.001$ \\
\hline Global Deterioration Scale (1-7) & $3.0 \pm 0.6(2-5)$ & $3.0 \pm 0.5(2-4)$ & $3.0 \pm 0.6(2-5)$ & $p=0.763$ \\
\hline Amnestic single domain $(\%)(n)$ & $15.8(29)$ & $13.5(10)$ & $17.4(19)$ & $p=0.476$ \\
\hline Amnestic multiple $(\%)(n)$ & $64.5(118)$ & $60.8(45)$ & $67.0(73)$ & $p=0.393$ \\
\hline Non-amnestic single $(\%)(n)$ & $8.7(16)$ & $14.9(11)$ & $4.6(5)$ & $p=\mathbf{0 . 0 1 6}$ \\
\hline Non-amnestic multiple $(\%)(n)$ & $10.9(20)$ & $10.8(8)$ & $11.0(12)$ & $p=0.966$ \\
\hline Pathological CSF biomarkers $(\% ; n=66)$ & $45.5(30)$ & $17.4(4)$ & $60.5(2)$ & $p=\mathbf{0 . 0 0 1}$ \\
\hline Concentration $\mathrm{A} \beta_{1-42}(n=66)$ & $637.5 \pm 261.2$ & $823.9 \pm 287.3$ & $537.8 \pm 182.0$ & $p<0.001$ \\
\hline Concentration T-tau $(n=67)$ & $411.9 \pm 242.1$ & $308.8 \pm 144.2$ & $465.8 \pm 265.8$ & $p=\mathbf{0 . 0 2 1}$ \\
\hline Concentration P-tau $181 \mathrm{P}(n=67)$ & $65.5 \pm 30.2$ & $51.8 \pm 19.5$ & $72.7 \pm 32.5$ & $p=0.014$ \\
\hline Free of psychotropic medication (\%) & 54.9 & 50.7 & 57.8 & $p=0.348$ \\
\hline Antidepressants (\%) & 24.0 & 28.8 & 20.6 & $p=0.212$ \\
\hline Antipsychotics (\%) & 4.5 & 4.1 & 4.8 & $p=0.821$ \\
\hline Hypnotics, sedatives, anxiolytics (\%) & 27.3 & 34.2 & 22.3 & $p=0.080$ \\
\hline Cholinesterase inhibitors (\%) & 1.1 & 0.0 & 1.9 & $p=0.235$ \\
\hline Antiparkinsonian agents (\%) & 1.7 & 2.7 & 1.0 & $p=0.369$ \\
\hline Antiepileptics (\%) & 2.2 & 4.1 & 0.9 & $p=0.164$ \\
\hline
\end{tabular}

Data are given as ratio, percentage or mean \pm SD with ranges represented between brackets. For comparison of male-female ratios and percentages, Chi-square statistics were used. For other comparisons, Mann-Witney U test was used. The level of significance was set at $p<0.05$.

complaints and loss of interest; (C) physical signs: appetite loss, weight loss and lack of energy; (D) cyclic functions: diurnal variation of mood, difficulty falling asleep, multiple awakenings during sleep and early morning awakening; (E) ideational disturbances: suicide, poor self-esteem, pessimism and mood-congruent delusions. The presence of significant depressive symptoms was defined by the CSDD as a total score of $>7$ [31]. Studies have shown the CSDD to be valid for screening depression in non-demented patients too [32].

The GDS-30 is a 30 -item self-rating scale developed to screen for depression in elderly people and can also be rated, as in this study, by an interview with the patient, even not requiring a trained interviewer [33]. The presence of significant depressive symptoms was defined by the GDS-30 as a total score $>11$ [33]. The GDS-30 is also a reliable screening tool for depressive symptoms in MCI [34].

For optimal interpretation of our data, we mentioned the score ranges of all assessment scales between brackets (x-y) in Tables $2 \& 3$.

\section{Cerebrospinal fluid (CSF) sampling and biomarker analyses}

Lumbar puncture, CSF sampling, and handling have been performed according to a standard proto- col [35]. CSF samples were stored at $-80^{\circ} \mathrm{C}$ until analysis.

CSF biomarker analyses of $\mathrm{A} \beta_{1-42}, \mathrm{~T}$-tau, and P-tau $181 \mathrm{P}$ were performed using commercially available single parameter ELISA kits (INNOTEST ${ }^{\circledR}$, Fujirebio Europe, Ghent, Belgium) at the BIODEM lab of Institute Born-Bunge/University of Antwerp as previously described [35].

A CSF biomarker profile was considered pathological and suggestive for $\mathrm{AD}$ if a subject displayed a low CSF $A \beta_{1-42}$ value in combination with an increased T-tau and/or increased P-tau $181 \mathrm{P}$ value (unpublished data). In our hands, and using the commercially available INNOTEST kits (Fujirebio Europe, Ghent), normal values are: $A \beta_{1-42}>638.50 \mathrm{pg} / \mathrm{mL}$, T-tau $<296.50 \mathrm{pg} / \mathrm{mL}$ and P-tau $181 \mathrm{P}<56.50 \mathrm{pg} / \mathrm{mL}$. These cutpoints have been determined in autopsyconfirmed AD patients as compared to cognitively healthy elderly (unpublished data).

\section{Statistical analyses}

The BPSD assessment scales used during this study provide semi continuous variables. The KolmogorovSmirnov test indicated that none of the used study variables could be treated as normally distributed. Therefore, non-parametric statistics were used: Kruskal-Wallis test and Mann-Whitney U tests 
Table 2

Baseline prevalence and severity of BPSD

\begin{tabular}{|c|c|c|c|c|c|c|}
\hline \multirow[b]{2}{*}{ Behavior/disturbances } & \multicolumn{3}{|c|}{ Prevalence $\%$} & \multicolumn{3}{|c|}{ Severity mean } \\
\hline & Stable $(n=74)$ & Progressive $(n=109)$ & Statistics & Stable $(n=74)$ & Progressive $(n=109)$ & Statistics \\
\hline MFS $\geq 5$ score/total $(0-10)$ & \multirow[t]{2}{*}{2.7} & \multirow[t]{2}{*}{4.6} & \multirow{2}{*}{$p=0.525$} & $1.7 \pm 1.5$ & \multirow{2}{*}{$\begin{array}{c}2.1 \pm 1.5 \\
(0-7)\end{array}$} & \multirow[t]{2}{*}{$p=0.145$} \\
\hline Frontal lobe symptoms & & & & $(0-6)$ & & \\
\hline Behave-AD (0-21) & \multirow[t]{2}{*}{5.4} & \multirow[t]{2}{*}{14.7} & \multirow{2}{*}{$p=\mathbf{0 . 0 4 8}$} & $0.1 \pm 0.5$ & \multirow{2}{*}{$\begin{array}{c}0.3 \pm 1.0 \\
(0-6)\end{array}$} & \multirow[t]{2}{*}{$p=0.045$} \\
\hline Delusions & & & & $(0-4)$ & & \\
\hline Behave-AD (0-15) & \multirow[t]{2}{*}{2.7} & \multirow[t]{2}{*}{6.4} & \multirow[t]{2}{*}{$p=0.254$} & $0.1 \pm 0.5$ & \multirow{2}{*}{$\begin{array}{c}0.2 \pm 0.7 \\
\quad(0-6)\end{array}$} & \multirow[t]{2}{*}{$p=0.265$} \\
\hline Hallucinations & & & & $(0-4)$ & & \\
\hline Behave-AD (0-36) & \multirow[t]{2}{*}{6.8} & \multirow[t]{2}{*}{17.4} & \multirow{2}{*}{$p=\mathbf{0 . 0 3 6}$} & $0.2 \pm 0.9$ & \multirow{2}{*}{$\begin{array}{c}0.5 \pm 1.5 \\
(0-11)\end{array}$} & \multirow[t]{2}{*}{$p=\mathbf{0 . 0 3 6}$} \\
\hline Psychosis & & & & $(0-6)$ & & \\
\hline Behave-AD (0-9) & \multirow[t]{2}{*}{16.2} & \multirow[t]{2}{*}{12.8} & \multirow[t]{2}{*}{$p=0.521$} & $0.2 \pm 0.5$ & $0.3 \pm 0.8$ & \multirow[t]{2}{*}{$p=0.653$} \\
\hline Activity & & & & $(0-3)$ & $(0-4)$ & \\
\hline Behave-AD (0-9) & \multirow[t]{2}{*}{51.4} & 54.1 & $p=0.712$ & $1.2 \pm 1.4$ & $1.5 \pm 1.8$ & $p=0.446$ \\
\hline Aggressiveness & & & & $(0-5)$ & $(0-7)$ & \\
\hline Behave-AD (0-3) & 41.9 & 26.6 & $p=\mathbf{0 . 0 3 1}$ & $0.5 \pm 0.7$ & $0.4 \pm 0.7$ & $p=0.052$ \\
\hline Diurnal rhythm & & & & $(0-3)$ & $(0-3)$ & \\
\hline Behave-AD (0-6) & 43.2 & 42.2 & $p=0.889$ & $0.8 \pm 1.2$ & $0.8 \pm 1.1$ & $p=0.966$ \\
\hline Affective & & & & $(0-5)$ & $(0-5)$ & \\
\hline Behave-AD (0-12) & 43.2 & 41.3 & $p=0.792$ & $0.7 \pm 0.9$ & $0.8 \pm 1.3$ & $p=0.939$ \\
\hline Anxiety/Phobias & & & & $(0-3)$ & $(0-8)$ & \\
\hline Behave-AD (0-75) & 85.1 & 86.2 & $p=0.834$ & $3.5 \pm 3.1$ & $4.2 \pm 3.9$ & $p=0.313$ \\
\hline Total score & & & & $(0-16)$ & $(0-22)$ & \\
\hline Behave-AD (0-3) & 29.2 & 35.2 & $p=0.399$ & $0.4 \pm 0.8$ & $0.4 \pm 0.6$ & $p=0.598$ \\
\hline Global score & & & & $(0-3)$ & $(0-3)$ & \\
\hline CMAI (10-70) & 0.0 & 0.0 & NA & $10.0 \pm 0.2$ & $10.0 \pm 0.2$ & $p=0.988$ \\
\hline Aggressive & & & & $(10-11)$ & $(10-12)$ & \\
\hline CMAI (11-77) & 21.9 & 18.5 & $p=0.574$ & $12.2 \pm 2.8$ & $12.0 \pm 2.6$ & $p=0.696$ \\
\hline Physically non-aggressive & & & & $(11-24)$ & $(10-28)$ & \\
\hline CMAI (8-56) & 46.6 & 53.7 & $p=0.347$ & $10.7 \pm 3.8$ & $11.7 \pm 4.8$ & $p=0.127$ \\
\hline Verbally agitated & & & & $(8-29)$ & $(8-34)$ & \\
\hline CMAI (29-203) & 54.8 & 63.0 & $p=0.272$ & $32.9 \pm 5.1$ & $33.7 \pm 6.5$ & $p=0.303$ \\
\hline Total score & & & & $(29-58)$ & $(29-72)$ & \\
\hline CSDD (0-38) & 12.2 & 16.5 & $p=0.415$ & $4.2 \pm 3.0$ & $4.3 \pm 3.3$ & $p=0.959$ \\
\hline$>7$ / total score & & & & $(0-12)$ & $(0-18)$ & \\
\hline GDS-30 (0-30) & 22.9 & 21.9 & $p=0.882$ & $8.0 \pm 4.7$ & $8.3 \pm 4.6$ & $p=0.514$ \\
\hline$\geq 12$ / total score & & & & $(1-19)$ & $(0-20)$ & \\
\hline
\end{tabular}

Data are given as percentages and mean scores \pm SD with ranges represented between brackets. For comparison of prevalence percentages, Chi-square statistics were used. For comparison of severity scores, Mann-Whitney U test was used. The level of significance was set at $p<0.05$.

were applied to compare (semi) continuous variables, Chi-square statistics for categorical data.

Cox proportional hazard models were fitted to test if a given variable could predict the time to change in diagnosis from a baseline of MCI to an endpoint of AD. To estimate the Hazard Ratios (HR) for incident $\mathrm{AD}, 95 \%$ confidence intervals $(\mathrm{CI})$ were used. All Cox proportional hazard models included age at baseline as a covariate. The significance of the variable of interest was tested using a likelihood ratio test, comparing the model with both age at baseline and the variable of interest, to a model containing only age at baseline.

Given the study objectives, focus was put on the stable MCI patients (no progress to dementia during our follow-up) in comparison with the AD progressive MCI patients. Nonetheless, in the end we also applied the Cox proportional hazard statistics to the data of all 235 MCI patients with a group of stable MCI patients compared to progressive MCI patients, considering all types of dementia as the other group, including the category 'unspecified' type of dementia.

Probability levels of $<0.05$ were considered significant. Statistical analyses were carried out using SPSS Statistics 17.0.

\section{RESULTS}

The follow-up outcomes from the 235 baseline MCI patients that met the study criteria were: (1) 74 'stable' MCI patients and (2) 161 'progressive' MCI patients progressed to dementia. From these 161: (a) 109 progressed to $\mathrm{AD}$, (b) 13 progressed to a non-AD dementia; and (c) 39 progressed to an unspecified type of dementia. So $69 \%(n=161)$ of the $235 \mathrm{MCI}$ patients progressed to any kind of dementia and at least $46 \%$ 
$(n=109)$ of the 235 MCI patients progressed to AD. The baseline characteristics of the study population are summarized in Table 1 . The average time in progressive patients to develop AD was 2 years (2.0 $\pm 1.6 \mathrm{SD})$. The mean time of clinical follow-up of stable patients was 4 years $(3.8 \pm 2.3 \mathrm{SD})$ with a minimum of one year and a maximum of 9 years. On average, the progressive patients were older at study inclusion and age at onset and had a lower MMSE at baseline.

Table 2 compares the prevalence and severity of BPSD between the stable and the progressive MCI patients. Delusions and psychosis are more prevalent and severe at baseline in progressive patients as compared to the stable MCI patients. Diurnal rhythm disturbances are more prevalent in stable MCI patients than in progressive, but mainly due to 'repetitive wakening during the night'. When it comes to more severe forms of diurnal rhythm disturbances, there is no difference in prevalence between stable and progressive MCI patients.

To study any difference in baseline BPSD between MCI subtypes or between men and women, we compared MFS, Behave-AD, CMAI, GDS-30, and CSDD total scores and Behave-AD global score. There was no difference in BPSD between the 4 MCI subtypes. Between men and women only the mean GDS-30 total score differed as women displayed more depressive symptoms than men $\left(\sigma^{7}: 7.4( \pm 4.1)\right.$ versus $\circ: 8.9( \pm 4.9)$, $p=0.035$ ).

Cox proportional hazards regression model (Table 3 ) adjusted for age (Fig. 1) demonstrated that the presence of depressive symptoms was associated with progression from MCI to AD. Significant depressive symptoms as measured by the CSDD doubled the hazard of progression to AD (Fig. 1). Significant depressive symptoms as measured by the GDS-30 are associated with a 77\% increased hazard of progression to AD. The presence of diurnal rhythm disturbances, associated with a $35 \%$ decreased hazard, appeared to be 'protective' for the progression to AD. Each 1-unit increase on the cluster verbally agitated behavior of the CMAI, was associated with a $6 \%$ increased hazard of progression; and each 1-unit increase on the total score of the CMAI, was associated with a $4 \%$ increased hazard. Also each 1-unit increase on the GDS-30 was associated with a $6 \%$ increased hazard of progression.

Additionally, we found that only the presence (HR: 2.00 ; 95\% CI: $1.12-3.59 ; p=0.032)$ and severity (HR: 1.58 ; $95 \%$ CI: $1.06-2.36 ; p=0.045)$ of 'purposeless activity' is a predictor for progression to $\mathrm{AD}$. The Behave-AD items 'Godot syndrome', 'fear of being left alone', 'other anxieties', 'other phobias',

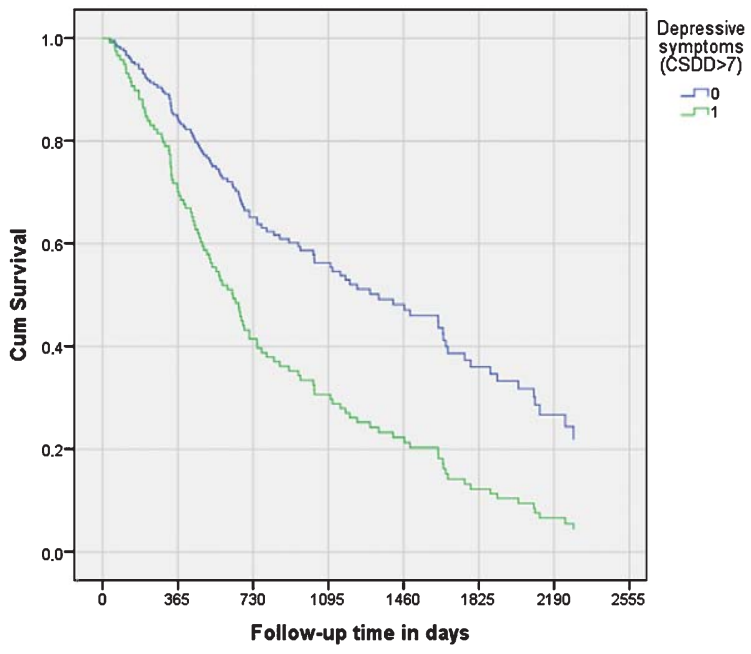

Fig. 1. Survival curve: Progression to AD related to depressive symptoms in MCI. The prediction of incident AD was estimated with Cox proportional hazards regression models, adjusted for age. Line 0: MCI patients without significant depressive symptoms based on CSDD $\leq 7(n=156)$. Line 1: MCI patients with significant depressive symptoms based on CSDD $>7(n=27)$. $p=0.011$.

'wandering away' and 'inappropriate activity' were no significant predictors for progression to AD.

Considering all MCI patients $(n=235)$ in a secondary analysis, we could only demonstrate that agitated behavior in MCI was associated with progression to dementia, especially verbal agitation. The presence of agitated behavior as measured by the total score of the CMAI was associated with a $46 \%$ increased hazard of progression to dementia (HR: 1.46; 95\% CI: $1.06-2.00 ; p=0.020$ ). Also each 1 -unit increase on the total score of the CMAI was associated with a $6 \%$ increased hazard of progression (HR: 1.06; 95\% CI: $1.02-1.10 ; p=0.003)$. The presence of verbally agitated behavior as measured by the CMAI was associated with a $67 \%$ increased hazard of progression to dementia (HR: 1.67; 95\% CI: $1.20-2.31$; $p=0.002$ ). Also each 1-unit increase on the cluster verbally agitated behavior of the CMAI was associated with a $4 \%$ increased hazard of progression (HR: 1.04; $95 \%$ CI: $1.01-1.07 ; p=0.012)$. In this analysis, we could not confirm that depressive symptoms were a predictor in MCI for progression to dementia (CSDD >7: $p=0.179$; CSDD total score: $p=0.540$; GDS-30 $\geq 12$ : $p=0.158$; GDS-30 total score: $p=0.136$ ). Moreover, other BPSD, like the presence of diurnal rhythm disturbances and the presence and severity of purposeless activity were no more significant predictors in MCI for the progression to dementia in this analysis. Sixty-six patients underwent lumbar puncture for CSF 
Table 3

MCI BPSD hazard ratios for progression to AD

\begin{tabular}{|c|c|c|c|c|c|c|}
\hline \multirow[t]{2}{*}{ Behavior/disturbances } & \multicolumn{3}{|c|}{ Present (dichotomous) } & \multicolumn{3}{|c|}{ (semi) Continuous } \\
\hline & HR & $95 \% \mathrm{CI}$ & Statistics & HR & $95 \% \mathrm{CI}$ & Statistics \\
\hline $\begin{array}{l}\text { MFS } \geq 5 \text { score / total }(0-10) \\
\text { Frontal lobe symptoms }\end{array}$ & 1.32 & $0.53-3.27$ & $p=0.571$ & 1.03 & $0.90-1.18$ & $p=0.689$ \\
\hline $\begin{array}{l}\text { Behave-AD }(0-21) \\
\text { Delusions }\end{array}$ & 1.60 & $0.93-2.73$ & $p=0.105$ & 1.12 & $0.92-1.35$ & $p=0.289$ \\
\hline $\begin{array}{l}\text { Behave-AD (0-15) } \\
\text { Hallucinations }\end{array}$ & 0.84 & $0.39-1.82$ & $p=0.646$ & 0.93 & $0.70-1.25$ & $p=0.630$ \\
\hline $\begin{array}{l}\text { Behave-AD (0-36) } \\
\text { Psychosis }\end{array}$ & 1.36 & $0.82-2.24$ & $p=0.252$ & 1.03 & $0.91-1.17$ & $p=0.669$ \\
\hline $\begin{array}{l}\text { Behave-AD (0-9) } \\
\text { Activity }\end{array}$ & 1.28 & $0.73-2.26$ & $p=0.407$ & 1.26 & $0.97-1.65$ & $p=0.107$ \\
\hline $\begin{array}{l}\text { Behave-AD (0-9) } \\
\text { Aggressiveness }\end{array}$ & 1.21 & $0.83-1.77$ & $p=0.327$ & 1.05 & $0.94-1.16$ & $p=0.395$ \\
\hline $\begin{array}{l}\text { Behave-AD (0-3) } \\
\text { Diurnal rhythm }\end{array}$ & 0.65 & $0.42-1.00$ & $p=0.045$ & 0.84 & $0.60-1.16$ & $p=0.269$ \\
\hline $\begin{array}{l}\text { Behave-AD (0-6) } \\
\text { Affective }\end{array}$ & 1.21 & $0.82-1.77$ & $p=0.347$ & 1.10 & $0.93-1.31$ & $p=0.286$ \\
\hline $\begin{array}{l}\text { Behave-AD (0-12) } \\
\text { Anxiety/Phobias }\end{array}$ & 1.08 & $0.73-1.59$ & $p=0.706$ & 1.07 & $0.91-1.25$ & $p=0.412$ \\
\hline $\begin{array}{l}\text { Behave-AD }(0-75) \\
\text { Total score }\end{array}$ & 1.13 & $0.65-1.95$ & $p=0.662$ & 1.03 & $0.98-1.08$ & $p=0.230$ \\
\hline $\begin{array}{l}\text { Behave-AD }(0-3) \\
\text { Global score }\end{array}$ & 1.45 & $0.97-2.17$ & $p=0.072$ & 1.07 & $0.83-1.38$ & $p=0.591$ \\
\hline $\begin{array}{l}\text { CMAI (10-70) } \\
\text { Aggressive }\end{array}$ & NA & NA & NA & 0.93 & $0.39-2.22$ & $p=0.864$ \\
\hline $\begin{array}{l}\text { CMAI (11-77) } \\
\text { Physically non-aggressive }\end{array}$ & 0.94 & $0.58-1.54$ & $p=0.812$ & 1.01 & $0.93-1.10$ & $p=0.811$ \\
\hline $\begin{array}{l}\text { CMAI (8-56) } \\
\text { Verbally agitated }\end{array}$ & 1.39 & $0.95-2.03$ & $p=0.092$ & 1.06 & $1.02-1.10$ & $p=\mathbf{0 . 0 1 2}$ \\
\hline $\begin{array}{l}\text { CMAI (29-203) } \\
\text { Total score }\end{array}$ & 1.48 & $1.00-2.19$ & $p=0.050$ & 1.04 & $1.01-1.07$ & $p=\mathbf{0 . 0 3 4}$ \\
\hline $\begin{array}{l}\text { CSDD }(0-38) \\
>7 / \text { total score }\end{array}$ & 2.06 & $1.23-3.44$ & $p=\mathbf{0 . 0 1 1}$ & 1.06 & $0.99-1.13$ & $p=0.082$ \\
\hline GDS-30 (0-30) & 1.77 & $1.10-2.85$ & $p=\mathbf{0 . 0 2 5}$ & 1.06 & $1.01-1.11$ & $p=\mathbf{0 . 0 2 0}$ \\
\hline
\end{tabular}

The prediction of incident AD was estimated with Cox proportional hazards regression models, adjusted for age. Hazard ratios (HR) with 95\% confidence intervals (CI) are reported for the associations of each BPSDvariable with incident AD. The level of significance was set at $p<0.05$.

biomarker analyses. From these 66 patients, 52 had their lumbar puncture within a 3 month time-linked interval with the study inclusion date. Pathological biomarker profiles pointing to $\mathrm{AD}$ were found in 22 patients (42\%). The progressive group had a higher percentage of patients with an AD pathological CSF biomarker profile. These biomarker profiles appeared to be a strong predictor for the progression to AD (HR: 5.57; 95\% CI: $2.46-12.61 ; p<0.001)$.

\section{DISCUSSION}

We conclude that the presence of significant depressive symptoms in MCI as measured by the CSDD (HR: 2.06 ; 95\% CI: $1.23-3.44 ; p=0.011$ ) and the GDS-30 (HR: 1.77 ; 95\% CI: $1.10-2.85 ; p=0.025$ ) are associated with an increased hazard of progression to AD. Also the severity of depressive symptoms as measured by the GDS-30 (HR: $1.06 ; 95 \% \mathrm{CI}$ : $1.01-1.11 ; p=0.020)$ is a predictor for progression to AD. Furthermore, the severity of agitated behavior, especially verbal agitation and the presence of purposeless activity are identified as predictors for progression AD.

From the secondary analysis, we learn that agitation in MCI is also a predictor for progression to dementia in general and that depressive symptoms in MCI are specific predictors for progression to $\mathrm{AD}$, as they were not significant for progression to unspecified dementia.

The dementia (69\%) and $\mathrm{AD}(\geq 46 \%)$ progression rates in our study are quite high as compared to other studies [5]. This might be due to strict application of the MCI definition, with objective cognitive impairment quantified as a performance of more than 1.5 SD below the appropriate mean on the neuropsychological subtests [5]; the research setting, being a specialized 
hospital-based setting, a memory clinic [5]; and strict in- and exclusion criteria focusing on a neurodegenerative MCI etiology [1, 2].

Depression is known to be associated with the incidence of MCI and dementia [36]. In some studies, also in MCI, depressive symptoms are associated with progression to $\mathrm{AD}$ or dementia [37, 38]. Our findings are in line with previous research, acknowledging that depression or depressive symptoms are of prognostic value for progression from MCI to AD [38-43], although this could not be demonstrated in some other studies [44-50]. One study even found a negative correlation between progression and the presence of affective symptoms [51]. Nevertheless, this conflicting evidence might be due to differences in study methodology, such as MCI definition, assessment instruments, sample size, statistics, follow-up term, research setting, etc. Furthermore, neither Gallagher et al. [45] nor our study could demonstrate a link between affective symptoms in MCI and progression to $\mathrm{AD}$ by means of the Behave-AD. The Behave-AD cluster affective disturbance was probably not specific enough towards depressive symptoms as compared to the CSDD and GDS-30 depression scales. Also in accordance with our results, Gallagher et al. [45] showed by means of the Behave-AD that purposeless activity was a significant clinical predictor for $\mathrm{AD}$ in MCI.

That diurnal rhythm disturbances are associated with no progression to $\mathrm{AD}$ is surprising, as circadian rhythm disturbances are frequent in AD [52-54] and in some studies even a predictor for the progression to dementia [55]. An explanation for our finding can be a lack of sensitivity of the Behave-AD cluster diurnal rhythm disturbances (that only consists of one item) in progressive MCI patients, as it is also known to be difficult to obtain accurate self-reports on sleep in demented patients [56].

Hazard ratios often indicate the risk for an event, but one could question to which extent depression is a true 'risk factor' versus an early symptom occurring in the prodromal AD stage. Panza et al. [57] concluded in 2010 that at least in certain subsets of older adults, late-life depression, MCI and dementia could represent a possible clinical continuum [57]. They hypothesized that the neuropathological and neurochemical changes that characterize AD can play a role in the etiopathogenesis of depressive symptoms [57]. So, assuming that MCI may be the earliest identifiable clinical stage of dementia, depressive symptoms may be an early manifestation rather than a risk factor for dementia and AD [57]. Recent studies provided also neuroanatomical [58, 59] and neurochemical [60] evidence to support this hypothesis.

Furthermore, we also found that severity of agitation in MCI, especially verbally agitated behavior, was predictive for progression to AD. Neuroanatomical studies about agitation in $\mathrm{MCI}$ and $\mathrm{AD}$ point toward involvement of frontal and temporal brain areas [61]. Recently Trzepacz et al. [61] and Tsai et al. [60] added evidence to this theory and confirmed the relation between agitation and AD pathology in these specific brain areas through neurodegeneration and neurochemical changes. Also worse cognitive performance on the MMSE correlated with AD-related brain changes in these two studies.

Moreover, the following hypothesis might also explain the interrelation between depression and agitation as predictors for progression to $\mathrm{AD}$. As described above, AD can play a role in the etiopathogenesis of depressive symptom. In addition, decreased serotonergic activity has been related to depression [62] and dopaminergic neurons are modulated by serotonergic innervation [63]. Indeed, the serotonergic system appears to have an inhibitory effect on the dopaminergic function [63, 64]. Furthermore, ascending dopaminergic pathways are part of the frontal-subcortical circuitry [65] and the dopaminergic system is one of the important modulators of frontal lobe function [66]. Consequently, frontal-subcortical circuit dysfunction leads to impaired executive functions, apathy and impulsivity [65] and might thus as well explain the prevalence and severity of agitation in $\mathrm{MCI}$ and $\mathrm{AD}$ patients.

Given our results, the interrelation of depression and agitation and recent neurochemical and neuroanatomical evidence, we may conclude that significant depressive symptoms and increased agitation are indeed early symptoms of AD rather than risk factors, which however has to be confirmed by future research.

This study has several strengths. First, this study is an up-to-9-year and still ongoing prospective longitudinal study. The continuous, even after AD progression, clinical and neuropsychological follow-up of included subjects contributed to increased diagnostic certainty of the population included. Second, the study included a well-characterized MCI population, diagnosed by strict application of stringent clinical diagnostic criteria and well monitored over time in our longitudinal protocol. Third, all patients were diagnosed by clinicians in the same center which preserves homogeneity in the MCI diagnostics and AD progression diagnoses. Fourth, we found homogeneous 
BPSD characteristics and AD progression rates in the four MCI subtypes of this study population. Consequently, no bias was introduced due to MCI BPSD or subtype heterogeneity. However, the absence of differences in BPSD comparing MCI subtypes might be due to limited statistical validity, because of relatively small subgroups of non-amnestic MCI patients included. Last but not least, though it was not the purpose of this study, we showed that a pathological AD biomarker profile was a strong predictor for progression to AD. Even though, these data were only available for a limited subgroup, the results were robust and in line with previous research $[67,68]$.

In 2013, mild and major neurocognitive disorders (NCD) were introduced as new categories in the 5th edition of the Diagnostic and Statistical Manual of Mental Disorders (DSM-5) with their own diagnostic criteria [69]. Their adoption in the DSM-5 is in fact an important recognition of MCI as a clinical diagnostic entity. The reason of acknowledgment in the DSM-5 is the same as the motivation of the National Institute of Aging-Alzheimer Association (NIA-AA) working groups [3] and the International Working Group (IWG) [70]: to facilitate the diagnosis of the very early stages of $\mathrm{AD}$, hoping for more successful therapeutic developments, through better research criteria. Mild and major NCD can also be 'due to AD', like 'MCI due to AD' (NIA-AA) or 'prodromal AD' (IWG). NCD covers the concept of MCI with a distinction between: mild, when the cognitive decline is modest without interference with complex instrumental activities of daily living; and major, when the cognitive decline is significant with a minimal interference with instrumental activities of daily living. In contrast with the new concepts of the NIA-AA and the IWG, biomarkers are not included in the NCD (due to AD) criteria.

Some study limitations are known to the authors. First, Table 3 shows the main results and several $p$-values that are nominally significant $(p<0.05)$, including the significant hazard ratios related to the presence of significant depressive symptoms (CSDD: $p=0.011$; GDS-30: $p=0.025)$ and the presence of diurnal rhythm disturbances $(p=0.045)$; and the significant hazard ratios related to the severity of agitation $(p=0.034)$, verbally agitated behavior $(p=0.012)$ and the severity of depressive symptoms (GDS-30: $p=0.020$ ). However, since we have tested multiple hypotheses, the risk of a false positive finding is inflated. Therefore, these significant associations should be regarded as interesting leads for further research rather than firm evidence of a strong association. Second, from 39 of the $235 \mathrm{MCI}$ patients that met our study criteria, we were not able to retrieve to which type of dementia they progressed. Third, our study population was recruited in a memory clinic, which might have introduced a selection bias as BPSD might have contributed to referral. Fourth, another bias is that some study subjects might have developed depressive symptoms as a psychological reaction to the cognitive decline [57]. Fifth, although some studies found apathy as a predictor factor for the progression to AD by application of Cox survival analysis [47, 48], we did not study the prognostic value of this specific symptom as no specific apathy assessment instrument was included in our study. Apathy has only been assessed partially through items 7 ' $(\ldots$ ) or emotional bluntness' and 8 'aspontaneity' of the MFS. Lastly, our study population was not free of psychotropic drug intake, as more than half of the study population was treated with at least one psychotropic drug at baseline. Consequently, these psychopharmacological agents may have influenced our results by masking potential associations through diminished BPSD.

Some studies use MMSE scores as part of their key eligibility criteria for MCI like the Alzheimer's Disease Neuroimaging Initiative which mentions MMSE scores 24-30 (inclusive) for MCI subjects as an inclusion criterion. This might raise questions about our MCI study population with a broad MMSE range (18-30). However, we would like to stress that the MMSE was only used for screening purposes. Besides, all patients underwent an extensive time-linked $( \pm 3$ months) neuropsychological examination with adjustment for gender, age and education, comprising amongst others the Wechsler Memory Scale, Hierarchic Dementia Scale and/or Repeatable Battery for the Assessment of Neuropsychological Status. This neuropsychological examination was used to test for the clinical diagnostic criteria for MCI and/or progression to $\mathrm{AD}$.

Depressive symptoms in MCI appear to be associated with progression to AD. Further research is important to unravel whether depression is a true 'risk factor' in MCI for the progression to AD or whether it is an early symptom of $\mathrm{AD}$.

\section{ACKNOWLEDGMENTS}

This research was supported by the University Research Fund of the University of Antwerp; the Foundation for Alzheimer Research (SAO-FRA); the Institute Born-Bunge; an unrestricted research grand form Lundbeck NV (Belgium); the agreement 
between the Institute Born-Bunge and the University of Antwerp; the central Biobank facility of the Institute Born-Bunge/University Antwerp; Neurosearch Antwerp; the Thomas Riellaerts Research Fund; the Research Foundation - Flanders (FWO-Vlaanderen); the Agency for Innovation by Science and Technology (IWT); the Interuniversity Attraction Poles (IAP) program P7/16 of the Belgian Science Policy Office; the Methusalem excellence grant of the Flemish Government, Belgium; and the Medical Research Foundation Antwerp. This work is part of the BIOMARKAPD project within the EU Joint Programme for Neurodegenerative Disease Research (JPND). This work has received support from the EU/EFPIA Innovative Medicines Initiative Joint Undertaking (EMIF grant $\mathrm{n}^{\circ}$ 115372). The authors acknowledge Prof. Dr. M. Elseviers (University of Antwerp), the administrative assistance of W. Wittebolle, S. Hicketick, A. Eyckens and the clinical staff involved (Hospital Network Antwerp).

Authors' disclosures available online (http://www.jalz.com/disclosures/view.php?id=2326).

\section{REFERENCES}

[1] Petersen RC (2004) Mild cognitive impairment as a diagnostic entity. J Intern Med 256, 183-194.

[2] Winblad B, Palmer K, Kivipelto M, Jelic V, Fratiglioni L, Wahlund LO, Nordberg A, Backman L, Albert M, Almkvist O, Arai H, Basun H, Blennow K, de Leon M, DeCarli C, Erkinjuntti T, Giacobini E, Graff C, Hardy J, Jack C, Jorm A, Ritchie K, van Duijn C, Visser P, Petersen RC (2004) Mild cognitive impairment-beyond controversies, towards a consensus: Report of the International Working Group on Mild Cognitive Impairment. J Intern Med 256, 240-246.

[3] Albert MS, Dekosky ST, Dickson D, Dubois B, Feldman HH, Fox NC, Gamst A, Holtzman DM, Jagust WJ, Petersen RC, Snyder PJ, Carrillo MC, Thies B, Phelps CH (2011) The diagnosis of mild cognitive impairment due to Alzheimer's disease: Recommendations from the National Institute on Aging-Alzheimer's Association workgroups on diagnostic guidelines for Alzheimer's disease. Alzheimers Dement 7, 270-279.

[4] Dierckx E, Engelborghs S, De Raedt R, De Deyn PP, PonjaertKristoffersen I (2007) Mild cognitive impairment: What's in a name? Gerontology 53, 28-35.

[5] Mitchell AJ, Shiri-Feshki M (2009) Rate of progression of mild cognitive impairment to dementia-meta-analysis of 41 robust inception cohort studies. Acta Psychiatr Scand 119, 252-265.

[6] Finkel SI, Costa e Silva, Cohen G, Miller S, Sartorius N (1996) Behavioral and psychological signs and symptoms of dementia: A consensus statement on current knowledge and implications for research and treatment. Int Psychogeriatr 8, 497-500.

[7] Van der Mussele S, Le Bastard N, Vermeiren Y, Saerens J, Somers N, Marien P, Goeman J, De Deyn PP, Engelborghs S (2013) Behavioral symptoms in mild cognitive impairment as compared with Alzheimer's disease and healthy older adults. Int J Geriatr Psychiatry 28, 265-275.

[8] Van der Mussele S, Marien P, Saerens J, Somers N, Goeman J, De Deyn PP, Engelborghs S (2014) Behavioral syndromes in mild cognitive impairment and Alzheimer's disease. $J$ Alzheimers Dis 38, 319-329.

[9] Monastero R, Mangialasche F, Camarda C, Ercolani S, Camarda R (2009) A systematic review of neuropsychiatric symptoms in mild cognitive impairment. J Alzheimers Dis $\mathbf{1 8}$, 11-30.

[10] Apostolova LG, Cummings JL (2008) Neuropsychiatric manifestations in mild cognitive impairment: A systematic review of the literature. Dement Geriatr Cogn Disord 25, 115-126.

[11] Folstein MF, Folstein SE, McHugh PR (1975) Mini-mental state. A practical method for grading the cognitive state of patients for the clinician. J Psychiatr Res 12, 189-198.

[12] The Psychological Corporation (1998) WAIS-III-WMS-III Technical Manual, Harcourt Brace \& Co, London.

[13] Randolph C, Tierney MC, Mohr E, Chase TN (1998) The Repeatable Battery for the Assessment of Neuropsychological Status (RBANS): Preliminary clinical validity. J Clin Exp Neuropsychol 20, 310-319.

[14] Cole MG, Dastoor DP (1987) A new hierarchic approach to the measurement of dementia. Accurate results within 15 to 30 minutes. Psychosomatics 28, 298-301, 304.

[15] McKhann G, Drachman D, Folstein M, Katzman R, Price D, Stadlan EM (1984) Clinical diagnosis of Alzheimer's disease: Report of the NINCDS-ADRDA Work Group under the auspices of Department of Health and Human Services Task Force on Alzheimer's Disease. Neurology 34, 939-944.

[16] American Psychiatric Association (2000) DSM-IV-TR: Diagnostic and Statistical Manual of Mental Disorders, Fourth Edition (Revised Text). American Psychiatric Association, Washington, DC.

[17] Le Bastard N, Coart E, Vanderstichele H, Vanmechelen E, Martin JJ, Engelborghs S (2013) Comparison of two analytical platforms for the clinical qualification of Alzheimer's disease biomarkers in pathologically-confirmed dementia. $J$ Alzheimers Dis 33, 117-131.

[18] Reisberg B, Ferris SH, de Leon MJ, Crook T (1982) The Global Deterioration Scale (GDS) for assessment of primary degenerative dementia. Am J Psychiatry 139, 1136-1139.

[19] Aries MJ, Le Bastard N, Debruyne H, Van Buggenhout M, Nagels G, De Deyn PP, Engelborghs S (2010) Relation between frontal lobe symptoms and dementia severity within and across diagnostic dementia categories. Int J Geriatr Psychiatry 25, 1186-1195.

[20] De Deyn PP, Engelborghs S, Saerens J, Goeman J, Marien P, Maertens K, Nagels G, Martin JJ, Pickut BA (2005) The Middelheim Frontality Score: A behavioural assessment scale that discriminates frontotemporal dementia from Alzheimer's disease. Int J Geriatr Psychiatry 20, 70-79.

[21] Reisberg B, Borenstein J, Salob SP, Ferris SH, Franssen E, Georgotas A (1987) Behavioral symptoms in Alzheimer's disease: Phenomenology and treatment. J Clin Psychiatry 48, 9-15.

[22] Cohen-Mansfield J (1996) Conceptualization of agitation: Results based on the Cohen-Mansfield Agitation Inventory and the Agitation Behavior Mapping Instrument. Int Psychogeriatr 8, 309-315.

[23] Choy CN, Lam LC, Chan WC, Li SW, Chiu HF (2001) Agitation in Chinese elderly: Validation of the Chinese version of the Cohen-Mansfield Agitation Inventory. Int Psychogeriatr 13, 325-335. 
[24] Cohen-Mansfield J, Marx MS, Rosenthal AS (1989) A description of agitation in a nursing home. J Gerontol 44, M77-M84.

[25] Gruber-Baldini AL, Boustani M, Sloane PD, Zimmerman S (2004) Behavioral symptoms in residential care/assisted living facilities: Prevalence, risk factors, and medication management. J Am Geriatr Soc 52, 1610-1617.

[26] Suh GH (2004) Agitated behaviours among the institutionalized elderly with dementia: Validation of the Korean version of the Cohen-Mansfield Agitation Inventory. Int $J$ Geriatr Psychiatry 19, 378-385.

[27] Testad I, Aasland AM, Aarsland D (2007) Prevalence and correlates of disruptive behavior in patients in Norwegian nursing homes. Int J Geriatr Psychiatry 22, 916-921.

[28] Zuidema SU, Derksen E, Verhey FR, Koopmans RT (2007) Prevalence of neuropsychiatric symptoms in a large sample of Dutch nursing home patients with dementia. Int J Geriatr Psychiatry 22, 632-638.

[29] Zuidema SU, de Jonghe JF, Verhey FR, Koopmans RT (2010) Environmental correlates of neuropsychiatric symptoms in nursing home patients with dementia. Int J Geriatr Psychiatry 25, 14-22.

[30] Alexopoulos GS, Abrams RC, Young RC, Shamoian CA (1988) Cornell Scale for Depression in Dementia. Biol Psychiatry 23, 271-284.

[31] Burns A, Lawlor B, Craig S (2004) Assessment Scales in Old Age Psychiatry, Martin Dunitz, London.

[32] Alexopoulos GS, Abrams RC, Young RC, Shamoian CA (1988) Use of the Cornell scale in nondemented patients. $J$ Am Geriatr Soc 36, 230-236.

[33] Yesavage JA, Brink TL, Rose TL, Lum O, Huang V, Adey M, Leirer VO (1982) Development and validation of a geriatric depression screening scale: A preliminary report. J Psychiatr Res 17, 37-49.

[34] Debruyne H, Van Buggenhout M, Le Bastard N, Aries M, Audenaert K, De Deyn PP, Engelborghs S (2009) Is the geriatric depression scale a reliable screening tool for depressive symptoms in elderly patients with cognitive impairment? Int J Geriatr Psychiatry 24, 556-562.

[35] Engelborghs S, De VK, Van de Casteele T, Vanderstichele H, Van EB, Cras P, Martin JJ, Vanmechelen E, De Deyn PP (2008) Diagnostic performance of a CSF-biomarker panel in autopsy-confirmed dementia. Neurobiol Aging 29, 11431159.

[36] Gao Y, Huang C, Zhao K, Ma L, Qiu X, Zhang L, Xiu Y, Chen L, Lu W, Huang C, Tang Y, Xiao Q (2013) Depression as a risk factor for dementia and mild cognitive impairment: $\mathrm{A}$ meta-analysis of longitudinal studies. Int J Geriatr Psychiatry 28, 441-449.

[37] Simard M, Hudon C, van RR (2009) Psychological distress and risk for dementia. Curr Psychiatry Rep 11, 41-47.

[38] Enache D, Winblad B, Aarsland D (2011) Depression in dementia: Epidemiology, mechanisms, and treatment. Curr Opin Psychiatry 24, 461-472.

[39] Teng E, Lu PH, Cummings JL (2007) Neuropsychiatric symptoms are associated with progression from mild cognitive impairment to Alzheimer's disease. Dement Geriatr Cogn Disord 24, 253-259.

[40] Steenland K, Karnes C, Seals R, Carnevale C, Hermida A, Levey A (2012) Late-life depression as a risk factor for mild cognitive impairment or Alzheimer's disease in 30 US Alzheimer's disease centers. J Alzheimers Dis $\mathbf{3 1}$, 265-275.

[41] Rosenberg PB, Mielke MM, Appleby BS, Oh ES, Geda YE, Lyketsos CG (2013) The association of neuropsychi- atric symptoms in MCI with incident dementia and Alzheimer disease. Am J Geriatr Psychiatry 21, 685-695.

[42] Modrego PJ, Ferrandez J (2004) Depression in patients with mild cognitive impairment increases the risk of developing dementia of Alzheimer type: A prospective cohort study. Arch Neurol 61, 1290-1293.

[43] Lee GJ, Lu PH, Hua X, Lee S, Wu S, Nguyen K, Teng E, Leow AD, Jack CR, Jr., Toga AW, Weiner MW, Bartzokis G, Thompson PM (2012) Depressive symptoms in mild cognitive impairment predict greater atrophy in Alzheimer's diseaserelated regions. Biol Psychiatry 71, 814-821.

[44] Devier DJ, Pelton GH, Tabert MH, Liu X, Cuasay K, Eisenstadt R, Marder K, Stern Y, Devanand DP (2009) The impact of anxiety on conversion from mild cognitive impairment to Alzheimer's disease. Int J Geriatr Psychiatry 24, 1335-1342.

[45] Gallagher D, Coen R, Kilroy D, Belinski K, Bruce I, Coakley D, Walsh B, Cunningham C, Lawlor BA (2011) Anxiety and behavioural disturbance as markers of prodromal Alzheimer's disease in patients with mild cognitive impairment. Int J Geriatr Psychiatry 26, 166-172.

[46] Palmer K, Berger AK, Monastero R, Winblad B, Backman L, Fratiglioni L (2007) Predictors of progression from mild cognitive impairment to Alzheimer disease. Neurology 68 , 1596-1602.

[47] Palmer K, Di IF, Varsi AE, Gianni W, Sancesario G, Caltagirone C, Spalletta G (2010) Neuropsychiatric predictors of progression from amnestic-mild cognitive impairment to Alzheimer's disease: The role of depression and apathy. $J$ Alzheimers Dis 20, 175-183.

[48] Richard E, Schmand B, Eikelenboom P, Yang SC, Ligthart SA, Moll van Charante EP, van Gool WA (2012) Symptoms of apathy are associated with progression from mild cognitive impairment to Alzheimer's disease in non-depressed subjects. Dement Geriatr Cogn Disord 33, 204-209.

[49] Robert PH, Berr C, Volteau M, Bertogliati C, Benoit M, Sarazin M, Legrain S, Dubois B (2006) Apathy in patients with mild cognitive impairment and the risk of developing dementia of Alzheimer's disease: A one-year follow-up study. Clin Neurol Neurosurg 108, 733-736.

[50] Robert PH, Berr C, Volteau M, Bertogliati-Fileau C, Benoit M, Guerin O, Sarazin M, Legrain S, Dubois B (2008) Importance of lack of interest in patients with mild cognitive impairment. Am J Geriatr Psychiatry 16, 770-776.

[51] Ramakers IH, Visser PJ, Aalten P, Kester A, Jolles J, Verhey FR (2010) Affective symptoms as predictors of Alzheimer's disease in subjects with mild cognitive impairment: A 10-year follow-up study. Psychol Med 40, 1193-1201.

[52] Ju YE, McLeland JS, Toedebusch CD, Xiong C, Fagan AM, Duntley SP, Morris JC, Holtzman DM (2013) Sleep quality and preclinical Alzheimer disease. JAMA Neurol 70, 587-593.

[53] Rothman SM, Mattson MP (2012) Sleep disturbances in Alzheimer's and Parkinson's diseases. Neuromolecular Med 14, 194-204.

[54] Weldemichael DA, Grossberg GT (2010) Circadian rhythm disturbances in patients with Alzheimer's disease: A review. Int J Alzheimers Dis 2010, pii: 716453.

[55] Somme J, Fernandez-Martinez M, Molano A, Zarranz JJ (2013) Neuropsychiatric symptoms in amnestic mild cognitive impairment: Increased risk and faster progression to dementia. Curr Alzheimer Res 10, 86-94.

[56] Bombois S, Derambure P, Pasquier F, Monaca C (2010) Sleep disorders in aging and dementia. $J$ Nutr Health Aging 14, 212-217.

[57] Panza F, Frisardi V, Capurso C, D'Introno A, Colacicco AM, Imbimbo BP, Santamato A, Vendemiale G, Seripa D, Pilotto 
A, Capurso A, Solfrizzi V (2010) Late-life depression, mild cognitive impairment, and dementia: Possible continuum? Am $J$ Geriatr Psychiatry 18, 98-116.

[58] Son JH, Han DH, Min KJ, Kee BS (2013) Correlation between gray matter volume in the temporal lobe and depressive symptoms in patients with Alzheimer's disease. Neurosci Lett 548, $15-20$

[59] Lee GJ, Lu PH, Hua X, Lee S, Wu S, Nguyen K, Teng E, Leow AD, Jack CR Jr, Toga AW, Weiner MW, Bartzokis G, Thompson PM (2012) Depressive symptoms in mild cognitive impairment predict greater atrophy in Alzheimer's diseaserelated regions. Biol Psychiatry 71, 814-821.

[60] Tsai CF, Hung CW, Lirng JF, Wang SJ, Fuh JL (2013) Differences in brain metabolism associated with agitation and depression in Alzheimer's disease. East Asian Arch Psychiatry 23, 86-90.

[61] Trzepacz PT, Yu P, Bhamidipati PK, Willis B, Forrester T, Tabas L, Schwarz AJ, Saykin AJ (2013) Frontolimbic atrophy is associated with agitation and aggression in mild cognitive impairment and Alzheimer's disease. Alzheimers Dement 9 , S95-S104.

[62] Coppen A (1967) The biochemistry of affective disorders. $\mathrm{Br}$ J Psychiatry 113, 1237-1264.

[63] Di Giovanni G, Esposito E, Di Matteo V (2010) Role of serotonin in central dopamine dysfunction. CNS Neurosci Ther 16, 179-194.

[64] Engelborghs S, Vloeberghs E, Le BN, Van BM, Marien P, Somers N, Nagels G, Pickut BA, De Deyn PP (2008)
The dopaminergic neurotransmitter system is associated with aggression and agitation in frontotemporal dementia. $\mathrm{Neu}$ rochem Int 52, 1052-1060.

[65] Bonelli RM, Cummings JL (2007) Frontal-subcortical circuitry and behavior. Dialogues Clin Neurosci 9, 141-151.

[66] Goldman-Rakic PS, Lidow MS, Gallager DW (1990) Overlap of dopaminergic, adrenergic, and serotoninergic receptors and complementarity of their subtypes in primate prefrontal cortex. J Neurosci 10, 2125-2138.

[67] Hansson O, Zetterberg H, Buchhave P, Londos E, Blennow K, Minthon L (2006) Association between CSF biomarkers and incipient Alzheimer's disease in patients with mild cognitive impairment: A follow-up study. Lancet Neurol 5, 228-234.

[68] Shaw LM, Vanderstichele H, Knapik-Czajka M, Figurski M, Coart E, Blennow K, Soares H, Simon AJ, Lewczuk P, Dean RA, Siemers E, Potter W, Lee VM, Trojanowski JQ (2011) Qualification of the analytical and clinical performance of CSF biomarker analyses in ADNI. Acta Neuropathol 121, 597-609.

[69] American Psychiatric Association (2013) DSM-5: Diagnostic and Statistical Manual of Mental Disorders, Fifth Edition. American Psychiatric Association, Washington, DC.

[70] Dubois B (2014) Improving diagnostic criteria for Alzheimer's disease - An update from the International Working Group. Lancet Neurol, in press. 